\title{
Metachronous lung cancer: The role of improved postoperative surveillance
}

Walter J. Scott, MD

See related article on page 836 .
From the Department of Surgical Oncology, Fox Chase Cancer Center, Philadelphia, Pa.

Received for publication Nov 18, 2003; accepted for publication Nov 24, 2003.

Address for reprints: Walter J. Scott, MD, Department of Surgical Oncology, Fox Chase Cancer Center, 7701 Burholme Ave, Philadelphia, PA 19111 (E-mail: W_Scott@fccc.edu).

J Thorac Cardiovasc Surg 2004;127:633-5 $0022-5223 / \$ 30.00$

Copyright ( $\odot 2004$ by The American Association for Thoracic Surgery

doi:10.1016/j.jtcvs.2003.11.052

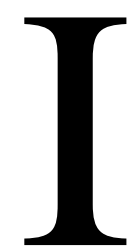

$\mathrm{n}$ this issue of the Journal, Battafarano and colleagues ${ }^{1}$ report their experience with resection of malignant lung tumors in 69 patients who had previously undergone resection of a malignant lung tumor. On the basis of a retrospective analysis, they found that resection of so-called metachronous lung tumors could be performed in selected patients with an acceptable surgical mortality rate $(5.8 \%)$ and meaningful long-term survival (5-year survival of $33.4 \%$ ). The authors note that the 5-year actuarial survival of patients who had metachronous stage I non-small cell lung cancer (NSCLC) resected was significantly longer than that in patients with more advanced metachronous lesions ( $42 \%$ vs $10 \%, P=.01)$. Most of the patients underwent anatomic resection of their metachronous lung tumors, but $42 \%$ underwent wedge resection, presumably because of limited pulmonary function. No mention was made of how these metachronous tumors were detected, whether through surveillance in otherwise asymptomatic patients or as a result of the evaluation of patients with symptoms or signs of recurrence. Given these findings, this article raises a number of questions about the clinical management of patients with a history of resected lung cancer who present with a new lung mass. Because patients with earlier stage metachronous tumors survived longer, the article also raises questions about the optimum follow-up of patients after potentially curative resection for lung cancer.

The authors point out that one major problem faced by the clinician is the differentiation of metachronous lung cancer from recurrent-metastatic lung cancer. Battafarano and colleagues ${ }^{1}$ used the criteria proposed by Martini and Melamed ${ }^{2}$ in 1975 to define a metachronous tumor as a second primary lung cancer (Table 1). Clinicians realize that misclassification of a metachronous tumor as a metastasis rather than a second primary lung cancer and vice versa still occurs, even if these criteria are followed. Despite this, the criteria of Martini and Melamed are generally accepted $^{3-5}$ or applied with modifications. ${ }^{6,7}$ Perhaps the specific criterion that is most commonly questioned is that a metachronous tumor of the same histologic type as the patient's first tumor should be considered a second primary tumor if it appeared at least 2 years after the diagnosis of the original lung cancer. In 1995, Martini and associates ${ }^{8}$ presented data from 598 patients who underwent complete resection of stage I NSCLC that showed that most (60\%) lung cancer recurrences in this group occurred within the first 2 years. However, in a series of 90 patients undergoing resection of second and third primary cancers, Mathisen and coworkers 9 found that there was a significant difference in survival of patients with second primary cancers who presented more than 3 years after treatment of the initial primary cancer. This suggests that a number of patients presenting with metachronous tumors between 2 and 3 years after their original tumor actually have metastatic disease and not a second primary cancer (or possibly that some second primary cancers develop more slowly and have a better prognosis). Perhaps to avoid this controversy, the investigators who designed the National Cancer Institute Intergroup Trial (NCI\#I91-0001), which demonstrated the inability of isotretinoin to prevent second primary tumors in patients after resection of stage I NSCLC, originally defined second primary lung cancers as those occurring 5 years after the original cancer was treated if the same histology was present in both tumors. ${ }^{10}$ Interestingly, Battafarano and colleagues ${ }^{1}$ found no difference in survival of their patients on the basis of a comparison of those presenting with a metachronous tumor 


\section{TABLE 1. Criteria for diagnosis}

\section{Metachronous tumors \\ A. Histology different \\ B. Histology the same if: \\ 1. free interval between cancers of at least 2 y or \\ 2. origin from carcinoma in situ or \\ 3. second cancer in different lobe or lung but \\ a. no carcinoma in lymphatics common to both \\ b. no extrapulmonary metastasis at time of diagnosis}

Adapted from Martini and Melamed.2

in the first 2 years after their original operation versus those who presented with a metachronous tumor after 2 years.

Although it seems clear that the longer the time interval from the primary cancer and its treatment the more likely it is that one is treating a second primary cancer, the specific time interval used as a criterion remains in question. Nevertheless, the length of time before presentation with a metachronous tumor when the histologic type is the same as that of the initial lung tumor remains an important criterion until a better one is found. Molecular biology will ultimately yield the best method for distinguishing recurrence-metastasis from second primary cancer. Investigators have evaluated small series of patients using DNA ploidy analysis ${ }^{11}$ and analysis of chromosome deletion patterns ${ }^{12}$ with some utility. However, the development of reliable and practical molecular biologic definitions requires prospective evaluation of tissue from greater numbers of patients with metachronous tumors. Finally, what also seems clear is that more data are required on the natural history of recurrence in the current era of treatment, in which patients receive multimodality treatments or adjuvant therapy or are enrolled in clinical trials of sublobar resection, radiofrequency ablation, or brachytherapy.

When a metachronous tumor is detected, how should it be treated? A careful staging evaluation should be performed to rule out extrathoracic sites of tumor. In the series presented by Battafarano and colleagues, ${ }^{1}$ anatomic resection was possible; however, $42 \%$ of patients were treated with wedge resection because of limited pulmonary function in these patients who had undergone one prior pulmonary resection. Additionally, the authors point out that their series represents $3 \%$ of all of the patients at their institution undergoing surgical intervention for NSCLC over a period of 14 years. Furthermore, they speculate that this probably underestimates the true incidence of metachronous tumors because their surgical database included only patients with sufficient lung function to undergo an operation. This points out the problem of limited lung function in treating this particular group of patients. As experience grows with currently novel therapies, such as radiofrequency ablation and stereotactic radiation therapy, these modalities might find application in the treatment of patients with metachronous tumors. The use of these techniques to treat early metachronous tumors might lead to an increase in the number of patients with these tumors who receive potentially curative therapy despite having limited pulmonary function.

How then should patients be followed after resection of early stage NSCLC? As mentioned earlier, Battafarano and colleagues ${ }^{1}$ found that the stage of the metachronous tumor correlated significantly with survival. This finding suggests that there might be a benefit to systematic postoperative surveillance of patients after resection, with the goal of detecting metachronous tumors at the earliest possible stage. The data in the current report are similar to data recently published by Rice and associates. ${ }^{13}$ They reported data from patients enrolled in the National Cancer Institute Chemoprevention Trial who had second primary lung cancers after resection of pathologic stage I NSCLC. ${ }^{10}$ Patients were followed with clinical examinations and semiannual chest radiographs. They found that the median survival of patients who were able to undergo resection of their metachronous tumor (4.1 years) was significantly longer that that for those who could not undergo resection because their metachronous tumors were detected at a more advanced stage (1.4 years, $P<.003$ ), again suggesting that surveillance might benefit patients through detection of resectable metachronous tumors. Rice and associates ${ }^{13}$ noted that despite semiannual chest radiography, $24 \%$ of the patients already had metastatic disease at the time of the diagnosis of their second primary lung cancer. Would chest computed tomography (CT) perform better? Chiu and coworkers ${ }^{14}$ recently reported that regular prospective follow-up of 43 patients after complete resection of NSCLC with low-dose helical CT detected significantly more recurrences than chest radiography alone, with most patients being asymptomatic at the time the recurrence was detected. This is not surprising given the information from lung cancer screening studies with low-dose helical CT in comparison with the plain chest radiograph. ${ }^{15}$ After complete resections for stage I NSCLC, patients develop second primary cancers at a rate of $2 \%$ per patient per year. ${ }^{13}$ After 5 years, that patient has a $10 \%$ chance of having a second primary lung cancer. Because clinical data show that postresection patients are at greater risk than any other group for development of a new (in this case, second) lung cancer, surveillance with lowdose spiral CT would seem to be of great potential benefit in this group. However, just as screening for initial lung cancer in high-risk individuals is controversial, so too is surveillance (ie, screening) for second primary lung cancers in individuals who have already had an initial lung cancer resected and for the same reasons: the biases associated with screening and the potential to cause harm with false-positive diagnoses. ${ }^{16}$ Only a randomized clinical trial of sufficient power could detect a true benefit in terms of mortality from lung cancer. The National Lung Screening Trial currently 
underway is just such a trial, albeit in patients who have not been previously treated for lung cancer. However, the results of this study are many years away.

Should we then agree with the experts who point out that postoperative surveillance is currently of no proven value and that unless a randomized controlled trial can be mounted, there is no reason to do more than what we do now: follow our patients on the basis of our own biases, with some surgeons obtaining chest radiographs, some obtaining CT scans, and some performing periodic physical examinations only until symptoms develop? I would propose instead that the thoracic surgical community attempt to answer the questions raised by articles such as the one by Battafarano and colleagues, ${ }^{1}$ if not through a randomized trial (as seems unlikely), then through a large, prospective, multicenter study with standardized means of follow-up, such as periodic, low-dose helical CT. The goals would be to determine the performance characteristics of low-dose helical CT in the postresection setting (pneumonectomy, lobectomy, segmentectomy, or wedge resection) and to determine the natural history of metachronous lung cancer in the current era given better staging and especially newer treatments, such as sublobar resections for small cancers. Although the detection of second primary lung cancers is important, the early detection of local recurrence has not been shown to be of much value because in most cases treatment is less than effective. However, single institutions have recently reported their experiences with sublobar resections for the treatment of selected patients with stage I NSCLC, and phase II clinical trials are being designed. ${ }^{17}$ Previous data suggest that sublobar resections alone are associated with a higher rate of local recurrence. ${ }^{18} \mathrm{~A}$ local recurrence after sublobar resection of a small peripheral tumor would likely be treatable by anatomic reresection or other means if detected early through routine surveillance, providing yet another reason to prospectively evaluate more effective methods of postoperative surveillance than the plain chest radiograph. A clinical trial of postoperative surveillance with low-dose helical CT should include a tissue bank of resected specimens, both initial cancers and metachronous tumors, enabling molecular biologists to work on better definitions of second primary tumors. This would also benefit patients presenting with synchronous lung tumors. And of course we should continue to support chemoprevention trials for this group of patients, such as the Intergroup Selenium Chemoprevention Trial (ECOG 5597).
If we choose not to do these things, then in 5 years, when another author writes about metachronous lung cancer, that editorial is likely to seem very similar to this one.

\section{References}

1. Battafarano RJ, Force SD, Meyers BF, et al. Benefits of resection for metachronous lung cancer. J Thorac Cardiovasc Surg. 2004;127:83642.

2. Martini N, Melamed MR. Multiple primary lung cancers: survival after resection of metachronous non-small cell lung cancer in 127 patients. J Thorac Cardiovasc Surg. 1975;70:606-12.

3. van Rens MT, Zanen P, de la Riviere AB, Elbers HRJ, van Swieten HA, van den Bosch JMM. Ann Thorac Surg. 2001;71:309-13.

4. Rea F, Zuin A, Callegaro D, Bortolottti L, Guanella G, Sartori F. Surgical results for multiple primary lung cancers. Eur J Cardiothorac Surg. 2001;20:489-95.

5. Aziz TM, Saad RA, Glasser J, Jilaihawi AN, Prakash D. The management of second primary lung cancers. A single centre experience in 15 years. Eur J Cardiothorac Surg. 2002;21:527-33.

6. Deschamps C, Pairolero PC, Trastek VF, Payne WS. Multiple primary lung cancers. J Thorac Cardiovasc Surg. 1990;99:769-78.

7. Antakli T, Schaefer RF, Rutherford JE, Read RC. Second primary lung cancer. Ann Thorac Surg. 1995;59:863-7.

8. Martini N, Bains MS, Burt ME, et al. Incidence of local recurrence and second primary tumors in resected stage I lung cancer. J Thorac Cardiovasc Surg. 1995;109:120-9.

9. Mathisen DJ, Jensik RJ, Faber LP, Kittle FC. Survival following resection for second and third primary lung cancers. J Thorac Cardiovasc Surg. 1984;88:502-10.

10. Lippman SM, Lee JJ, Karp DD, et al. Randomized phase III intergroup trial of isotretinoin to prevent second primary tumors in stage I non-small-cell lung cancer. J Natl Cancer Inst. 2001;93:605-18.

11. Ichinose Y, Hara N, Ohta M, Kuda T, Asoh H, Chikama H. DNA ploidy patterns of tumors diagnosed as metachronous or recurrent lung cancer. Ann Thorac Surg. 1991;52:469-73.

12. Leong PP, Rezai B, Koch WM, et al. Distinguishing second primary tumors from lung metastases in patients with head and neck squamous cell carcinoma. J Natl Cancer Inst. 1998;90:972-7.

13. Rice D, Kim H, Sabichi A, et al. The risk of second primary tumors after resection of stage I nonsmall cell lung cancer. Ann Thorac Surg. 2003;76:1001-8.

14. Chiu C-H, Chern M-S, Wu M-H, et al. Usefulness of low-dose spiral $\mathrm{CT}$ of the chest in regular follow-up of postoperative non-small cell lung cancer patients: preliminary report. J Thorac Cardiovasc Surg. 2003;125:1300-5.

15. Henschke CI, McCauley DI, Yankelevitz DF, et al. Early lung cancer action project: overall design and findings from baseline screening. Lancet. 1999;354:99-105.

16. Swensen SJ. CT screening for lung cancer. AJR Am J Roentgenol. 2002;179:833-6.

17. Santos R, Colonias A, Parda D, et al. Comparison between sublobar resection and Iodine brachytherapy after sublobar resection in highrisk patients with Stage I non-small-cell lung cancer. Surgery. 2003; 134:691-7.

18. Ginsberg RJ, Rubinstein LV. Randomized trial of lobectomy versus limited resection for T1 N0 non-small cell lung cancer. Lung Cancer Study Group. Ann Thorac Surg. 1995;60(3):615-22. 